\title{
HSD10 disease
}

INSERM

\section{Source}

INSERM. (1999). Orphanet: an online rare disease and orphan drug data base. HSD10 disease. ORPHA:391417

HSD10 disease is a rare, life-threatening neurometabolic disease characterized by a progressive neurodeg enerative course, epilepsy, retinopathy and prog ressive cardiomyopathy. 